\title{
Palmomental Reflex a Relevant Sign in Early Alzheimer's Disease Diagnosis?
}

\author{
Audrey Gabelle ${ }^{\mathrm{a}, \mathrm{b}, \mathrm{d}, *}$, Laure-Anne Gutierrez ${ }^{\mathrm{a}, \mathrm{c}, \mathrm{d}}$, Jean-François Dartigues ${ }^{\mathrm{e}}$, Karen Ritchie ${ }^{\mathrm{c}, \mathrm{d}}$, \\ Jacques Touchon ${ }^{\mathrm{a}, \mathrm{c}, \mathrm{d}}$ and Claudine Berr ${ }^{\mathrm{a}, \mathrm{c}, \mathrm{d}}$ \\ ${ }^{a}$ Memory Research and Resources Center, CMRR of Montpellier, Department of Neurology, \\ Hospital Gui de Chauliac, Montpellier, France \\ bINSERM U1183, Saint Eloi Hospital, Montpellier, France \\ ${ }^{\mathrm{c}}$ INSERM U1061, La Colombière Hospital, Montpellier, France \\ ${ }^{\mathrm{d}}$ Montpellier University, Montpellier, France \\ ${ }^{\mathrm{e}}$ Memory Research and Resources Center, CMRR de Bordeaux, Bordeaux, France
}

Accepted 30 September 2015

\begin{abstract}
.
Background: Sophisticated and expensive biomarkers are proposed for the diagnostic of Alzheimer's disease (AD). The amyloid process seems to be early in $\mathrm{AD}$, and brain amyloid load affects the frontal lobe.

Objective: To determine if certain simple clinical signs, especially frontal-related signs, could help reach an earlier and better diagnosis.

Methods: In the frame of the 3-City cohort, we conducted a nested case-control study comparing incident cases of AD to controls matched for age, gender, and education. The standardized neurological exam included extrapyramidal signs (akinesia, rigidity, rest tremor), pyramidal symptoms (spastic rigidity, Babinski reflex), primitive reflexes (snout, palmomental reflex grasping), and tremor (essential, intentional, head) at the time of diagnosis and two years before.

Results: We compared 106 incident AD subjects (mean age at diagnosis 82.2 ( $\mathrm{SD}=5.9$ ); median MMSE at diagnosis $=23$ ) to 208 matched controls. In patients younger than 80, palmomental reflexes were more frequent in AD than controls, two years before diagnosis ( 25.0 versus $7.0 \%, p=0.03$ ) and at time of diagnosis ( 30.3 versus $12.3 \%, p=0.02$ ). No difference was observed for other signs two years before diagnosis or for patients older than 80 .

Conclusion: Before diagnosis, the clinical examination of AD patients is not strictly normal; the primitive reflexes appear to be pathological. It might be in connection with the frontal amyloid load at an early stage of the disease. Clinical examination can reveal simple and interesting signs that deserve consideration as well as the other more invasive and expensive biomarkers.
\end{abstract}

Keywords: Alzheimer's disease, biomarkers, clinical examination, frontal signs, palmomentonal reflex

\section{INTRODUCTION}

On the hypothetical dynamic's curve of biomarkers' appearance for the diagnosis of Alzheimer's disease (AD) $[1,2]$, clinical signs seem to appear late after the positivity of in vivo biomarkers reflecting the amyloid

\footnotetext{
${ }^{*}$ Correspondence to: Dr. Audrey Gabelle, Memory Research and Resources Center, CMRR of Montpellier, Department of Neurology, Montpellier University Hospital Gui de Chauliac, F-34295 Montpellier, France. Tel.: +33 4673360 29; Fax: +3346733 60 36; E-mail: a-gabelle@chu-montpellier.fr.
}

process and the tau neuronal injury. The development of brain imaging amyloid markers, based on the amyloid cascade theory of Hardy [3, 4], gives us anatomical information regarding the amyloid load. The aim is to underline in vivo amyloid plaques in the brain regions of interest that reflect the AD process. In the first human study comparing Pittsburgh Compound-B (PIB) retention in 16 mild AD patients versus 9 controls, the PIB retention was increased most prominently in frontal cortex (1.94-fold, $p=0.0001)$ in the AD patients [5]. If large increases were also observed in parietal, 
temporal, and occipital cortices [5], other studies validated, on visual inspection of the PIB images, a greater binding in the orbitofrontal, posterior cingulate, and precuneus (for review, see Saidlitz et al. [6]). Amyloid load assessed on PET scan may be also a risk marker of progression of healthy and mild cognitive impairment (MCI) subjects to AD [7-9]. Literature data show that 20 to $30 \%$ of healthy elderly subjects have increased amyloid. In these subjects, amyloid load progresses during follow-up, as shown in a study [10] that followed 24 non-demented subjects, mean age 79 years, for 1.5 years \pm 6 months and found that PIB retention increased by $0.9 \%$ annually. The increase was greater in subjects who had high amyloid deposition at baseline, mainly in the prefrontal, parietal, lateral temporal, occipital, and anterior and posterior cingulate cortices. Moreover, certain regions of amyloid deposits (prefrontal, posterior cingular, lateral temporal cortices) appear to be more predictive of risk of progression of amnestic MCI subjects toward dementia disorder [11]. On the other hand, some neuropsychiatric signs like apathy or irritability seem to belong to the spectrum of prodromal AD symptoms $[12,13]$. No study underlines the presence of frontal clinical signs at an early stage of AD. We assume that clinical signs could help in a better and earlier diagnosis of $\mathrm{AD}$ and in particular specific clinical signs such as frontal release signs (snout, palmomental, grasping ... ) in relation with the frontal (pre-frontal, lateral frontal) amyloid load at an early stage [14-16]. To address this hypothesis, we explored whether neurological signs could be present at an early stage of $\mathrm{AD}$ in a subsample of the French Three-City (3C), a prospective cohort study of noninstitutionalized subjects aged 65 and over, followed during 12-years with an exhaustive and systematic clinical examination at each follow-up.

\section{MATERIALS AND METHODS}

\section{Study design}

The French 3C study (three French cities: Bordeaux, Montpellier, and Dijon) is a population-based study of non-institutionalized subjects aged $\geq 65$ aiming to determine the relationship between vascular factors and dementia [17, 18]. A nested case-control study [19] is designed based on the 2,259 participants stemming from the Montpellier cohort followed every two years during a 12-year period with standardized and detailed neurological examination.

This neurological examination was carried out for all individuals by a trained practitioner at each follow- up. Each practitioner was trained by the same senior neurologist (JT) during all follow-ups. A systematic procedure for the neurological exam was fulfilled by the practitioner. A particular focus on extrapyramidal signs (akinesia, rigidity, rest tremor), pyramidal symptoms (spastic rigidity, Babinski' sign), primitive reflexes (snout, palmomental, grasp), and tremor (essential (action/postural), intentional, head) classified in 0 (absent) or 1 (present) is performed.

To test akinesia, as a change of the initiation and the automatic execution of the movements, the slowing down and the rarity of the harmonious character of the gesture, we analyzed rapid alternative movements, gait impairments, and reduced facial expression (mask-like). For extrapyramidal rigidity, we analyzed the sustained "lead pipe" resistance throughout the range of motion affecting flexor and extensor muscles equally. Cog wheeling may be brought out when the examiner passively moves an elbow or wrist. This sign is increased by reinforcement maneuvers such as having the patient use the opposite hand to trace circles in the air. Asymmetric resting tremor corresponds to regular rhythmic tremor (frequency 4-6 Hertz) observed when the patient sits, hands on the knees. To detect the palmomental reflex, the skin of the patient is scratched near the thenar eminence by a key. When present, there is a brief contraction of the ipsilateral mentalis muscle with puckering the chin. The essential tremor included postural- or action-type tremor. It pertains to the abnormal oscillation around the axis when the postural manoeuver hand in tension is performed. The intentional tremor presents characteristics of cerebellar signs, the tremor appears when patients are asked to touch their nose with their fingers, oscillations are more marked when the target is reached.

The diagnosis of dementia is established at each follow-up using a two-step procedure. First, the evaluation of neuropsychological tests (Mini-Mental State Examination (MMSE), the Isaacs Set Test, and the Benton Visual Retention Test) is performed by trained psychologists [20] and the subject is systematically examined by a neurologist. Second, an independent committee of neurologists reviewed all potential cases of dementia in order to obtain a consensus based on the Diagnostic and Statistical Manual of Mental Disorders (DSM-IV) criteria and NINCDS-ADRDA criteria for AD diagnosis. We excluded the 41 prevalent dementia cases for which clinical signs before diagnosis were unavailable, and the 66 incident dementia other than AD. Thus, the cases were the incident AD cases that were identified during the 12-year followup $(n=106)$. Two controls per case were randomly 
sampled from the set of those at risk i) under followup on the date the case was diagnosed, ii) of the same gender, age $( \pm 2.5$ years $)$, and educational attainment (4 classes: primary, secondary, college, and university as described in Table 1). We constitute a group of 208 matched controls ( 4 cases has only 1 matchedcontrols).

All patients gave their written informed consent to participate in this research study.

The study protocol was approved by the Ethical Committee of the Institutional Review Board at Kremlin-Bicêtre University Medical Center.

\section{Statistical analysis}

Clinical signs variables are evaluated as binary characteristics. First we compared cases and controls using Chi2 test (for qualitative variables) or Wilcoxon's test (for quantitative variables). Multiple conditional logistic regressions were used to estimate the odds ratios with their $95 \%$ confidence intervals in matched casescontrol analysis [21,22]. We analyzed the neurological signs at time of diagnosis and two years before. Secondary, we performed the same analysis in two groups according to age: $<80$ years-old/ $\geq 80$ years old. Analyses were performed using the SAS software (version 9.2, SAS Institute Inc., Cary, NC).

\section{RESULTS}

\section{Sample characteristics at time of diagnosis (Tables 1 and 2)}

In the incident $\mathrm{AD}$ cases, the mean age was 82.2 $(\mathrm{SD}=5.9), 19.8 \%$ were highly educated, the median MMSE was 23 [14-28], 20.4\% presented with a MMSE $\geq 26$ and $58.3 \%$ a MMSE between 21 and 26 . All cognitive scores were lower in the AD dementia group than in controls $(p<0.001)$. At baseline, no difference was observed between groups for vascular risk factors (diabetes mellitus, blood pressure, alcohol consumption, tobacco abuse, BMI, and presence of cardiovascular diseases) (data not shown).

Clinical signs two years before and at the time of the AD dementia diagnosis in the entire population (Table 3)

At time of diagnosis, akinesia (30.7 versus $17.6 \%$, $\mathrm{OR}=2.44, p=0.004$ ), palmomental primitive reflex (22.6 versus $12.1 \%, \mathrm{OR}=2.30, p=0.02$ ), and essential tremor $(17.3$ versus $8.51 \%, \mathrm{OR}=2.16, p=0.03)$ were

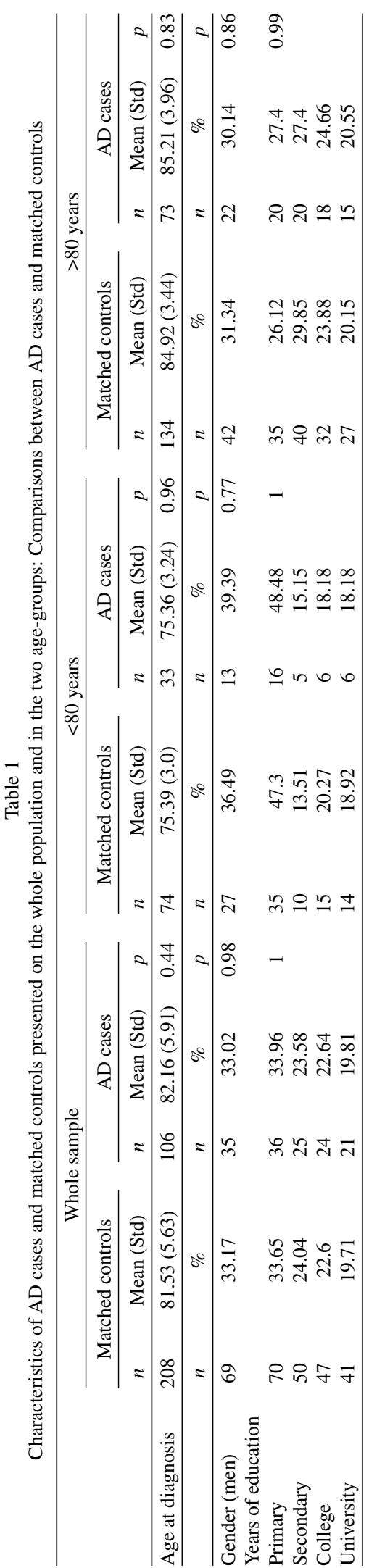




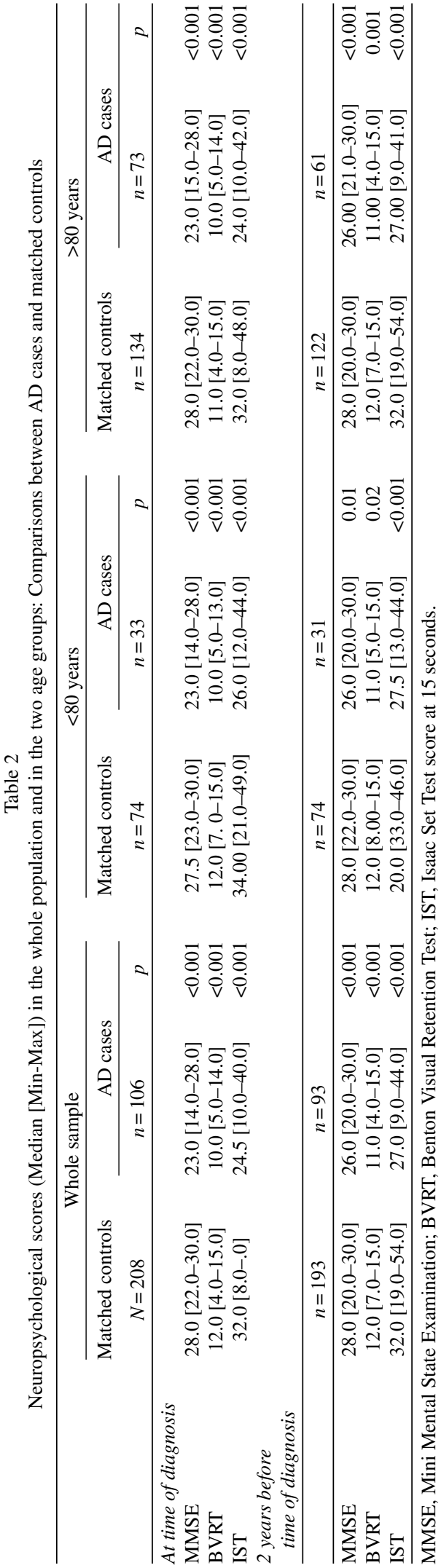

more frequent in incident $\mathrm{AD}$ cases than in controls. Two years before, no clinical sign differed between incident $\mathrm{AD}$ cases and controls in the entire population.

\section{Clinical signs in patients younger than 80 years} old (Fig. 1)

Interestingly, in younger patients (less than 80 years old) the palmomental reflex was more frequent in $\mathrm{AD}$ patients than in controls ( 25.0 versus $7.0 \%, p=0.03$ ) two years before. This result persists at the time of diagnosis (30.3 versus $12.3 \%, p=0.02$ ).

Akinesia (43.5 versus $23.8 \%, p=0.001)$ and essential tremor (21.1 versus $11.8 \%, p=0.035)$ were more frequent in older $\mathrm{AD}$ patients ( $\geq 80$ years-old) at the time of diagnosis only. No difference was observed for grasp reflexes, Babinski's sign, others types of tremor, plastic or spastic hypertonia, or others neurological clinical signs.

\section{DISCUSSION}

To the best of our knowledge, this is the first report highlighting that primitive reflexes were present and relevant for $\mathrm{AD}$ diagnosis at an early stage in patients younger than 80 years. Two years before diagnosis, palmomental reflex could help discriminate young AD patients from controls. The palmomental reflex might be an useful warning sign in routine clinical practice. Our results challenge the dogma of the normal clinical examination in $\mathrm{AD}$ patients at an early stage of the disease [23].

Primitives reflexes such as palmomental, snout, and grasp reflexes are present from birth and can be associated with feeding and attachment to the mother. They disappear as the frontal part of the brain matures. In healthy subjects, the primitive reflexes are often present and the prevalence increases with age as described in the large sample of the Maastricht Aging study [24]. It seems that primitive reflexes appear commonly after the age of 66 years. As the 3C study included subjects older than 65 , we took into account the effect of age by matching controls to AD cases in regards to age. For specific dementia diagnosis, studies usually report a lack of specificity and sensibility of these reflexes particularly the palmomental [25]. However, the exact prevalence of such primitive reflexes is unknown because of the variability in the means of eliciting these reflexes and the interpretation of their presence. In dementia patients, the presence of primitive reflexes has been linked to the severity of the dementia in a prospective study of 2914 Canadians 
Table 3

Frequency of neurological clinical signs between incident AD cases and matched controls at time of diagnosis and two years before ( $p$ value are based on results of conditional logistic regression comparing $\mathrm{AD}$ and controls)

\begin{tabular}{|c|c|c|c|c|c|c|c|c|}
\hline & \multicolumn{4}{|c|}{ At time of diagnosis } & \multicolumn{4}{|c|}{ Two years before diagnosis } \\
\hline & $\begin{array}{c}\text { Matched controls } \\
\quad n=208\end{array}$ & AD cases & OR [CI 95\%] & $\begin{array}{c}p \\
n=106\end{array}$ & Matched controls & $\begin{array}{c}\text { AD cases } \\
n=208\end{array}$ & $\begin{array}{c}\text { OR [CI 95\%] } \\
n=106\end{array}$ & $p$ \\
\hline Akinesia & $35(17.6 \%)$ & $31(30.7 \%)$ & $2.44[1.32-4.49]$ & 0.004 & $30(15.6 \%)$ & $19(21.1 \%)$ & $2.09[0.96-4.52]$ & 0.06 \\
\hline Snout reflex & $55(27.6 \%)$ & $37(36.3 \%)$ & $1.72[0.91-3.27]$ & 0.01 & $56(29.3 \%)$ & $35(38.9 \%)$ & $1.63[0.87-3.04]$ & 0.13 \\
\hline Palmomental reflex & $24(12.1 \%)$ & $23(22.6 \%)$ & $2.30[1.17-4.52]$ & 0.02 & $22(11.5 \%)$ & $17(18.9 \%)$ & $1.64[0.82-3.29]$ & 0.17 \\
\hline Rigidity & $12(6.03 \%)$ & $12(11.8 \%)$ & $2.14[0.92-5.01]$ & 0.08 & $10(5.21 \%)$ & $6(6.67 \%)$ & $1.60[0.51-5.10]$ & 0.42 \\
\hline Essential tremor & $17(8.50 \%)$ & $18(17.3 \%)$ & $2.16[1.06-4.41]$ & 0.03 & $13(6.77 \%)$ & $9(10.0 \%)$ & $1.68[0.68-4.14]$ & 0.26 \\
\hline
\end{tabular}

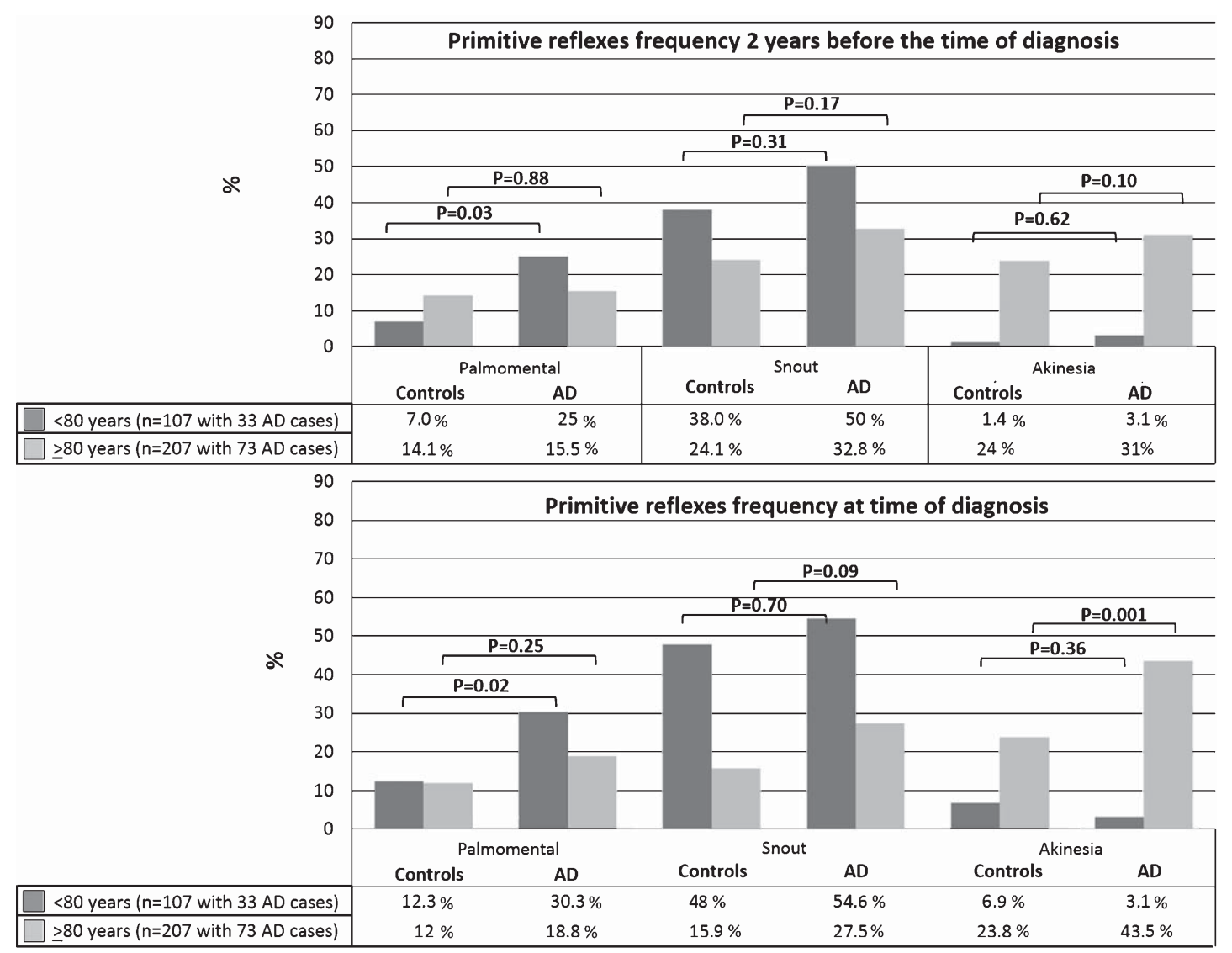

Fig. 1. Effects of primitive reflexes (palmomental, snout) and akinesia clinical signs between 106 incident AD cases and 208 matched controls in two age groups (<or $\geq 80$ years old) two years before or at time of AD diagnosis.

over 65 , with a higher frequency in patients with severe dementia than at an earlier stage of the disease [26]. In a systematic description of 204 cases of dementia, primitive reflexes appear to be more indicative of advanced age, severity of the illness, and diagnosis of Lewy body disease or mixed dementia [27]. In the present study, we unveiled interestingly that palmomental primitive reflexes were pathologic early on in the AD process in patients younger than 80 years, a point that had never been examined in previous studies. The reasons why these clinical signs were only pathologic in younger patients remain hypothetical but one explanation might be the high prevalence of amyloid lesions in the frontal area in normal elderly people, observed, for example, in amyloid imaging studies, contributing to decreasing the difference between $\mathrm{AD}$ and non-AD in older people. Another hypothetical explanation might reside in the fact that older patients present a different $\mathrm{AD}$ clinical phenotype with less frontal-related signs and more akinetic symptoms related to the impact of vascular mixed brain lesions. The palmomental reflexes could be interpreted as a frontal-released reflex. Some 
neuropsychological and brain imaging studies underlined that frontal areas are pathologic at a prodromal stage of the disease. Frontal-related apathy could be considered as an early biomarker of AD diagnosis [28-30]. In the same way, the amyloid PET-scan studies at a prodromal stage of $\mathrm{AD}$ revealed that amyloid load is predominant on frontal areas such as dorsolateral frontal areas [7]. In this study, the diagnosis of $\mathrm{AD}$ is based on the NINCDS-ADRDA diagnosis criteria and on a consensus adjudicative committee. As all the convertors and/or controls has not undergone brain imaging to exclude vascular changes in frontal lobes, we could not exclude that some vascular lesions are the cause of the positivity of frontal release signs.

A major strength of our work is the framework of a longitudinal follow-up and systematic neurological exam implemented in the 3C-Montpellier cohort. Clinical signs were documented at each wave and can be studied two years before the diagnosis, so interpretation is not influenced by cognitive complaint or status and reflects the AD prodromal phase. However, we cannot exclude inter-operator differences in the interpretation of the presence of each clinical sign despite the fact that all physicians who examined participants have been trained to standardize the exam in the Neurology unit (JT, AG) associated closely to the epidemiological team.

\section{CONCLUSION}

Primitive reflexes can be tested easily and rapidly in clinical routine. Even if the sensibility of these signs is far from perfect, their presence may alert the clinician to the possibility of brain pathology, even at an early stage. The standardized examination with primitive reflexes evaluation should be included or re-included in the neurological bedside screening of patients with early $\mathrm{AD}$ degenerative process.

\section{ACKNOWLEDGMENTS}

The 3C Study is conducted under a partnership agreement between the Institut National de la Santé et de la Recherche Médicale (INSERM), VictorSegalen Bordeaux-2 University, and Sanofi-Aventis. The Fondation pour la Recherche Médicale funded the preparation and initiation of the study. The 3C Study is also supported by the Caisse Nationale Maladie des Travailleurs Salariés, Direction Générale de la Santé, MGEN, Institut de la Longévité, Conseils Régionaux d'Aquitaine et Bourgogne, Fondation de France and Ministry of Research - INSERM Programme "Cohortes et collections de données biologiques", Agence Nationale de la Recherche ANR PNRA 2006 and Longvie 2007 and Fonds de coopération scientifique Alzheimer (FCS 2009-2012).

Authors' disclosures available online (http://j-alz. com/manuscript-disclosures/15-0436r2).

\section{REFERENCES}

[1] Dubois B, Feldman HH, Jacova C, Cummings JL, Dekosky ST, Barberger-Gateau P, Delacourte A, Frisoni G, Fox NC, Galasko D, Gauthier S, Hampel H, Jicha GA, Meguro K, O'Brien J, Pasquier F, Robert P, Rossor M, Salloway S, Sarazin M, de Souza LC, Stern Y, Visser PJ, Scheltens P (2010) Revising the definition of Alzheimer's disease: A new lexicon. Lancet Neurol 9, 1118-1127.

[2] Jack CR Jr, Knopman DS, Jagust WJ, Shaw LM, Aisen PS, Weiner MW, Petersen RC, Trojanowski JQ (2010) Hypothetical model of dynamic biomarkers of the Alzheimer's pathological cascade. Lancet Neurol 9, 119-128.

[3] Hardy JA, Higgins GA (1992) Alzheimer's disease: The amyloid cascade hypothesis. Science 256, 184-185.

[4] Hardy J, Selkoe DJ (2002) The amyloid hypothesis of Alzheimer's disease: Progress and problems on the road to therapeutics. Science 297, 353-356.

[5] Klunk WE, Engler H, Nordberg A, Wang Y, Blomqvist G, Holt DP, Bergstrom M, Savitcheva I, Huang GF, Estrada S, Ausen B, Debnath ML, Barletta J, Price JC, Sandell J, Lopresti BJ, Wall A, Koivisto P, Antoni G, Mathis CA, Langstrom B (2004) Imaging brain amyloid in Alzheimer's disease with Pittsburgh Compound-B. Ann Neurol 55, 306-319.

[6] Saidlitz P, Voisin T, Vellas B, Payoux P, Gabelle A, Formaglio M, Delrieu J (2014) Amyloid imaging in Alzheimer's disease: A literature review. J Nutr Health Aging 18, 723-740.

[7] Villemagne VL, Pike KE, Chetelat G, Ellis KA, Mulligan RS, Bourgeat P, Ackermann U, Jones G, Szoeke C, Salvado O, Martins R, O'Keefe G, Mathis CA, Klunk WE, Ames D, Masters CL, Rowe CC (2011) Longitudinal assessment of Abeta and cognition in aging and Alzheimer disease. Ann Neurol 69, 181-192.

[8] Morris JC, Roe CM, Grant EA, Head D, Storandt M, Goate AM, Fagan AM, Holtzman DM, Mintun MA (2009) Pittsburgh compound $\mathrm{B}$ imaging and prediction of progression from cognitive normality to symptomatic Alzheimer disease. Arch Neurol 66, 1469-1475.

[9] Ossenkoppele R, van Berckel BN, Prins ND (2011) Amyloid imaging in prodromal Alzheimer's disease. Alzheimers Res Ther 3, 26.

[10] Sojkova J, Zhou Y, An Y, Kraut MA, Ferrucci L, Wong DF, Resnick SM (2011) Longitudinal patterns of beta-amyloid deposition in nondemented older adults. Arch Neurol 68, 644649.

[11] Koivunen J, Scheinin N, Virta JR, Aalto S, Vahlberg T, Nagren K, Helin S, Parkkola R, Viitanen M, Rinne JO (2011) Amyloid PET imaging in patients with mild cognitive impairment: A 2-year follow-up study. Neurology 76, 1085-1090.

[12] Delrieu J, Desmidt T, Camus V, Sourdet S, BoutoleauBretonniere C, Mullin E, Vellas B, Payoux P, Lebouvier T (2015) Apathy as a feature of prodromal Alzheimer's disease: An FDG-PET ADNI study. Int J Geriatr Psychiatry 30, 470-477. 
[13] Apostolova LG, Cummings JL (2008) Neuropsychiatric manifestations in mild cognitive impairment: A systematic review of the literature. Dement Geriatr Cogn Disord 25, 115-126.

[14] Chetelat G, Villemagne VL, Bourgeat P, Pike KE, Jones G, Ames D, Ellis KA, Szoeke C, Martins RN, O'Keefe GJ, Salvado O, Masters CL, Rowe CC (2010) Relationship between atrophy and beta-amyloid deposition in Alzheimer disease. Ann Neurol 67, 317-324.

[15] Leinonen V, Alafuzoff I, Aalto S, Suotunen T, Savolainen S, Nagren K, Tapiola T, Pirttila T, Rinne J, Jaaskelainen JE, Soininen H, Rinne JO (2008) Assessment of betaamyloid in a frontal cortical brain biopsy specimen and by positron emission tomography with carbon 11-labeled Pittsburgh Compound B. Arch Neurol 65, 1304-1309.

[16] Armstrong RA (2015) Laminar distribution of beta-amyloid (Abeta) peptide deposits in the frontal lobe in familial and sporadic Alzheimer's disease. Folia Neuropathol 53, $15-23$.

[17] Lambert JC, Schraen-Maschke S, Richard F, Fievet N, Rouaud O, Berr C, Dartigues JF, Tzourio C, Alperovitch A, Buee L, Amouyel P (2009) Association of plasma amyloid beta with risk of dementia: The prospective Three-City Study. Neurology 73, 847-853.

[18] (2003) Vascular factors and risk of dementia: Design of the Three-City Study and baseline characteristics of the study population. Neuroepidemiology 22, 316-325.

[19] Berr C, Gabelle A, Fievet N, Goldberg M, Zins M, Carriere I (2015) How to optimize the use of biobanks from populationbased cohorts in aging research. Biogerontology. 2015 Jun 26. [Epub ahead of print] PMID: 26112233.

[20] Gabelle A, Richard F, Gutierrez LA, Schraen S, Delva F, Rouaud O, Buee L, Dartigues JF, Touchon J, Lambert JC, Berr C (2013) Plasma amyloid-beta levels and prognosis in incident dementia cases of the 3-City Study. J Alzheimers Dis 33, 381-391.
[21] Breslow NE, Day NE (1980) Statistical methods in cancer research. Volume I - The analysis of case-control studies. IARC Sci Publ 5-338.

[22] Moulin JJ, Wild P, Romazini S, Lasfargues G, Peltier A, Bozec C, Deguerry P, Pellet F, Perdrix A (1998) Lung cancer risk in hard-metal workers. Am J Epidemiol 148, 241-248.

[23] Poncet M, Guinot H (1989) [Clinical aspects and course of Alzheimer's disease]. Rev Prat 39, 462-465.

[24] van Boxtel MP, Bosma H, Jolles J, Vreeling FW (2006) Prevalence of primitive reflexes and the relationship with cognitive change in healthy adults: A report from the Maastricht Aging Study. J Neurol 253, 935-941.

[25] Owen G, Mulley GP (2002) The palmomental reflex: A useful clinical sign? J Neurol Neurosurg Psychiatry 73, 113-115.

[26] Hogan DB, Ebly EM (1995) Primitive reflexes and dementia: Results from the Canadian Study of Health and Aging. Age Ageing 24, 375-381.

[27] Links KA, Merims D, Binns MA, Freedman M, Chow TW (2010) Prevalence of primitive reflexes and Parkinsonian signs in dementia. Can J Neurol Sci 37, 601-607.

[28] Robert PH, Clairet S, Benoit M, Koutaich J, Bertogliati C, Tible O, Caci H, Borg M, Brocker P, Bedoucha P (2002) The apathy inventory: Assessment of apathy and awareness in Alzheimer's disease, Parkinson's disease and mild cognitive impairment. Int J Geriatr Psychiatry 17, 1099-1105.

[29] Robert PH, Berr C, Volteau M, Bertogliati C, Benoit M, Sarazin M, Legrain S, Dubois B (2006) Apathy in patients with mild cognitive impairment and the risk of developing dementia of Alzheimer's disease: A one-year follow-up study. Clin Neurol Neurosurg 108, 733-736.

[30] Robert PH, Berr C, Volteau M, Bertogliati-Fileau C, Benoit M, Guerin O, Sarazin M, Legrain S, Dubois B (2008) Importance of lack of interest in patients with mild cognitive impairment. Am J Geriatr Psychiatry 16, 770-776. 